\title{
La diversidad de las emociones
}

\section{Isabel Cabrera}

Olbeth Hansberg, La diversidad de las emociones.

México, FCE, 1996.

$\mathrm{E}$

1 libro La diversidad de las emociones de Olbeth Hansberg es un análisis de cinco emociones que todos conocemos: el miedo, el orgullo, el enojo, el resentimiento y la indignación. Su propósito es defender condiciones necesarias de cada una de estas emociones, esclareciendo parcialmente así su significado. El conjunto conforma una clara elucidación que, no obstante, sugiere dos formas distintas de acercarse a las emociones. Una manera, ejemplificada por Hansberg en el caso de las dos primeras, el miedo y el orgullo, es aislar la emoción y preguntarse qué tipo de creencias, deseos y estados físicos supone dicha emoción. Así, los dos primeros capítulos tejen fino respecto de algunas discusiones filosóficas contemporáneas sobre estos puntos. Las otras tres emociones, en cambio, el enojo, el resentimiento y la indignación, conforman un único capítulo final, y aunque aquí las discusiones sobre las condiciones necesarias de dichas emociones no son tan detalladas como en los casos anteriores, se señalan algunos parentescos que mantienen entre sí y que dan una luz indirecta sobre su naturaleza. De cualquier manera, el procedimiento que más le interesa a la autora es el de aislar una emoción de otras, e intentar detectar creencias, deseos y/o estados físicos indispensables para la presencia de dicha emoción.

A pesar de la preferencia de Hansberg, el acercamiento de su último capítulo me parece en general más adecuado. Creo que las emociones, como las creencias, por lo común vienen en enjambre, y quizá la mejor manera de precisar su naturaleza sea justamente la de describir esta complejidad; complejidad que incluye, no sólo las relaciones con creencias y deseos sino asimismo combinaciones entre dicha emoción y otras emociones y sentimientos. Hansberg dice, al inicio de su texto, que son los escritores quienes mejor describen las emociones, pero en las ocasiones en las que utiliza este recurso, lo hace siempre a manera de ejemplos. A mí me parece, sin embar- 
go, que los textos literarios podrían aducirse, más que para ejemplificar un análisis, para iniciarlo o complementarlo significativamente. En las parábolas de Kafka, por ejemplo, hay descripciones de miedos llenos de incertidumbre, miedos salpicados con asco, miedos resignados, miedos teñidos de indignación, etcétera. Me pregunto si no será que el miedo, el miedo en particular, es una compleja familia de emociones, todas ellas emparentadas entre sí aunque no siempre de forma transitiva, de tal manera que no quepa señalar algo constante o común.

Hansberg respondería que sí hay algo en común en todos estos miedos, algo específico que cuando falta no se presenta la emoción. Pero yo no estoy tan segura de que esto sea así. En el primer capítulo del libro encontramos esta discusión. Creo que Hansberg tiene razón, en contra de Gordon, al señalar que no todo miedo implica incertidumbre: parece obvio que tiene menos miedo quien teme resbalarse de un barandal que quien ya está cayendo al vacío con la certeza de que se va a dar un golpe terrible. No obstante, hay dos rasgos del miedo que Hansberg argumenta como constantes: el deseo de que no ocurra lo temido y un peculiar estado físico. Esta segunda condición reduce en forma significativa el miedo, dejando fuera los ejemplos del propio Gordon donde se temen cosas pero no se siente nada a nivel corporal (como "temo que lloverá"), pero también se dejan fuera -y esto es quizá más grave- los terrores que se disfrazan de arrojo y temeridad y los miedos profundos, inconscientes, más no por ello irracionales - no por ello aislados de nuestra conducta y nuestras creencias-, que muchas veces, como señaló Freud, se ponen los ropajes del deseo.

En cuanto a la primera condición, el deseo de que no suceda lo temido, pienso que es más general pero que también cuenta con contraejemplos. ¿Quién no ha sentido alguna vez temor frente a la inminente satisfacción de un deseo largamente añejado? Pero cuando se tiene miedo de enfrentar lo que uno ha deseado por mucho tiempo, no siempre sucede que lo realmente temido es la posibilidad del fracaso o la decepción. Sin duda, hay quien teme la satisfacción de un deseo porque teme decepcionarse y quien teme el compromiso porque teme el fracaso, pero hay veces en las que este temor no implica ningún deseo negativo, sino expresa más bien un respeto, una veneración hacia el objeto del temor. En esta línea está, según me parece, lo que suele llamarse "temor religioso" o "temor a Dios" del que habla el judaísmo, donde en lo temido no hay nada no deseado, y el temor es más bien reflejo de lo que Schleiermacher llamaba un "sentimiento de absoluta dependencia". Pero quizá pueda encontrarse un ejemplo más cotidiano de esto en otro pariente del temor: el suspenso, el cual en más de una ocasión se produce como una mezcla de impaciencia e incertidumbre que no lleva consigo ningún deseo negativo. 
Quizá no todas nuestras emociones sean de esta naturaleza y tengan la misma complejidad. No se me presenta la misma inquietud respecto al análisis que hace Hansberg del orgullo. En este caso creo que la conclusión a la que nos conduce es peculiarmente atractiva porque señala nuestra capacidad de compartir un valor a través del orgullo. Sentimos orgullo -defiende Hansberg- no sólo porque valoramos algo, sino asimismo porque tenemos algún sentimiento de pertenencia respecto a ello. Quizá por esto sea tan difícil sentir orgullo en medio de un estado depresivo; quien padece depresión o quien intenta animar a un amigo deprimido sabe que muchas veces los caminos para sentir orgullo están truncados. O bien el deprimido no es capaz de reconocer el valor en las cosas que ama, que le pertenecen y a las que pertenece, o bien las valora pero no acepta que él tenga con ellas una relación que pueda transmitirle ese valor. Entonces el valor no nos toca, no nos atañe.

El texto de Hansberg me despierta un tercer comentario. En el primer capítulo se dice que las emociones humanas, a diferencia de las emociones de otros animales, pueden ser "proposicionales". Según lo entiendo, lo que esto quiere decir es que las emociones humanas tienen dos rasgos que no podemos atribuir a los animales: el holismo de lo mental (una emoción se da ligada a creencias, actitudes y deseos), y la autoconciencia (no sólo sentimos cosas sino además nos damos cuenta de que las sentimos). Los animales no tienen estas capacidades o, cuando menos, nosotros no sabemos que las tengan. En este punto, discrepo de Hansberg. Me parece que tanto el holismo mental como la autoconciencia, son conceptos graduales que pueden existir en una menor escala en otros seres vivos. Me remito a dos ejemplos. En un libro de etología leí lo siguiente: a un simio, que ha convivido por años con seres humanos, le enseñan a separar en dos grupos un conjunto de fotografias, de un lado fotografías de seres humanos, del otro, fotografias de cualesquiera otros animales. El simio va paulatinamente separando las fotografías, y cuando ve la suya, la pone sin dudar en el montón de los humanos, mientras que deja al resto de los antropoides en el otro montón. Si el ejemplo es fiable, ¿no refleja esta conducta un cierto grado de autoconciencia y una cierta complejidad mental? El otro ejemplo podría darlo, quizá, cualquiera que conviva con un perro y sepa de la capacidad que tienen estos animales para simular; simulan no oír cuando se les llama y no quieren venir, fingen no ver la comida que no les gusta, simulan no estar cuando sospechan que van a ser bañados. Hansberg diría que en realidad el perro ni finge ni simula, ésta es sólo una manera de hablar, a falta de otras más precisas y correctas. Decimos que simula porque no tenemos otra forma de expresar lo que hace, pero usamos los términos de manera analógica y no descriptiva. Pero si podemos atribuir, en este caso al perro, algún nivel de complejidad 
mental y algún grado -aunque sea precario- de autoconciencia, no veo por qué no aceptar que la predicación es descriptiva aunque, por supuesto, el perro no sea capaz de simulaciones tan sofisticadas como aquellas en las que nos escudamos los humanos.

Para concluir quisiera señalar una riqueza del texto que, no obstante, no ha sido explotada por su autora. Un fino análisis sobre las emociones resulta ser un eslabón indispensable en muchas discusiones éticas, religiosas, políticas o existenciales. De aquí que la mayor parte de los filósofos que realizan un análisis de este tipo, tengan detrás un trasfondo más amplio de problemas que son aquello sobre lo cual se habrá de aplicar dicho análisis. En el texto que aquí comentamos, dicho trasfondo está ausente; es como si Hansberg nos ofreciera generosamente una herramienta de precisión que ella misma no utiliza aquí pero que, con seguridad, utilizará en un próximo texto. Esto convierte a La diversidad de las emociones en un libro que no sólo tiene interés por sí mismo, sino también porque puede ayudar a iluminar y resolver problemas de muy diversa índole. 